* Doutora em Direito pela Universidade Federal de Santa Catarina - UFSC, Especialista em Direito Constitucional, com ênfase em Direito Municipal, pela Universidade Luterana do Brasil (2005), Mestrado em Direito pela Universidade de Santa Cruz do Sul (2006). Atualmente é professora adjunta da Universidade Federal de Santa Maria - UFSM, Coordenadora do Grupo de Estudos de Direito e Consumo Sustentável -GEDCS da UFSM.

E-mail: daniela.richter@ufsm.br

**Possui graduação em Ciências Jurídicas e Sociais pela Universidade Federal de Santa Maria (1995), graduação em Letras Português Inglês pela Faculdade de Filosofia Ciências e Letras Imaculada Conceição (1994) e mestrado em Direito pela Universidade do Vale do Rio dos Sinos (2001). Atualmente é sócia - Brunet Advogados Associados e docente do Curso de Direito da Antônio Meneghetti Faculdade.

E-mail: knbrunet@hotmail.com

***Advogado Graduado pela Faculdade Metodista Centenário de Santa Maria-RS.

E-mail: odonefp@yahoo.com.br

\section{O Land Grabbing E A Estrangeirização das Propriedades Brasileiras E a luta Contra As Novas Formas De Colonialismo}

\author{
Land Grabbing And The Strangerization Of \\ Brazilian Properties And The Fight Against New \\ Forms OF COLONIALisM
}

\section{Daniela Richter* Karina Schuch Brunet** Odone Frederico Paul***}

Como citar: RICHTER, Daniela; BRUNET, Karina Schuch; PAUL, Odone Frederico. O land grabbing e a estrangeirização das propriedades brasileiras e a luta contra as novas formas de colonialismo. Revista do Direito Público, Londrina, v. 16, n. 3, p. 144-167, dez. 2021. DOI: 10.5433/24157-108104-1.2021v16 n3p.144. ISSN: 1980-511X

Resumo: O presente trabalho versa sobre o land grabbing e a estrangeirização das propriedades brasileiras por meio de um olhar pluralista e intercultural dos direitos humanos na luta contra as novas formas de colonialismo. Quer justamente analisar se esse fenômeno pode ser considerado uma nova forma de colonialismo no Brasil e na América Latina. E, desse modo, se seriam os direitos humanos uma saída contra hegemônica de poder na sua perspectiva pluralista e intercultural. Possui como objetivo descrever a luta pela terra como direito humano no Brasil, perpassando pelas formas de como os estrangeiros podem realizar a aquisição territorial e sobre os modos de colonização existentes. Objetiva, ademais, analisar o land grabbing com um olhar crítico, a fim de descrevê-lo não apenas como um procedimento de aquisição de terras, mas como forma de exploração e de poder quando utilizados por grandes grupos econômicos, para ao final, ponderar e enfrentar a possibilidade dos direitos humanos ser, ou não, uma resposta contra hegemônica de poder. Para tanto, utiliza-se o método de abordagem dedutivo, e de procedimento monográfico, utilizando-se da técnica de pesquisa bibliográfica.

Palavras-Chave: Direitos Humanos; Colonialismo; Estrangeirização de terras brasileiras; Land Grabbing; Pluralismo.

Abstract: The present work deals with land grabbing and the foreignization of Brazilian properties through a pluralist and intercultural view of human rights in the fight against new forms 
of colonialism. It intends to analyze whether this phenomenon can be considered a new form of colonialism in Brazil and Latin America. And, in this way, if human rights would be a counter-hegemonic way out of power in its pluralistic and intercultural perspective. It aims to describe the struggle for land as a human right in Brazil, going through the ways in which foreigners can acquire land and the existing modes of colonization. It also aims to analyze land grabbing with a critical eye, in order to describe it not only as a procedure of land acquisition, but also as a form of exploitation and power when used by large economic groups. To do so, the deductive method of approach is used, as well as the monographic procedure, using the bibliographical research technique.

Keywords: Human rights. Colonialism. Estrangeirization of Brazilian lands. Land Grabbing. Pluralism. 


\section{INTRODUÇÃO}

O presente trabalho tem como tema a análise do land grabbing e a estrangeirização das propriedades brasileiras por meio de um olhar pluralista e intercultural dos direitos humanos na luta contra as novas formas de colonialismo. Trata-se de tema atual e relevante, desconhecido por muitos e que têm gerado muitas polêmicas. Quer analisar se o fenômeno conhecido como land grabbing pode ser considerado uma nova forma de colonialismo no Brasil. E, desse modo, se seriam os direitos humanos uma saída contra hegemônica de poder na sua perspectiva pluralista e intercultural. Objetiva, primeiramente, descrever a luta pela terra como direito humano no Brasil, perpassando pelas formas de como os estrangeiros podem realizar a aquisição territorial e sobre os modos de colonização existentes.

Para tanto, far-se-á a descrição do referido processo a fim de descrevê-lo não apenas como um procedimento de aquisição de terras, mas como forma de exploração e de poder quando utilizados por grandes grupos econômicos. Ao final, busca-se ponderar e enfrentar a possibilidade dos direitos humanos ser, ou não, uma resposta contra hegemônica de poder.

Utiliza-se o método de abordagem dedutivo, visto que a pesquisa partirá de uma análise geral do acesso à terra ao caso específico da aquisição de terras por estrangeiros e o fenômeno do land grabbing. Logo, a fim de responder o problema que norteia a presente pesquisa, partir-se-á de um panorama geral para, ao fim, analisar tais preceitos a partir de um caso específico. Quanto ao método de procedimento, utiliza-se o monográfico, que consiste no estudo de determinados indivíduos com o intuito de obter generalidades, o qual será empregado em virtude da análise dos obstáculos enfrentados na concretização dos direitos humanos como uma resposta contra hegemônica de poder. Quanto à técnica de pesquisa, tem-se a utilização da bibliográfica, tendo em vista a análise dos documentos e doutrinas existentes a respeito da temática. É o que se passa a demonstrar.

\section{A LUTA PELA TERRA COMO DIREITO HUMANO NO BRASIL: ANÁliSE DAS FORMAS DE AQUISIÇÃO PELOS ESTRANGEIROS}

Inicialmente, é importante dizer que se fará uma breve conceituação de direitos humanos e de sua importância, para, após, trabalhar o seu desdobramento enquanto acesso à terra.

Quanto à concepção de Direitos Humanos, pode-se afirmar que é a partir do segundo pósguerra que surgem os primeiros movimentos em sua defesa, num cenário de total reconstrução. "A criação das Nações Unidas simboliza o surgimento de uma nova ordem internacional e inaugura um novo modelo de conduta nas relações internacionais" (GOTTI; RICARDO, 2002, p. 313). Nessa órbita, em 10 de dezembro de 1948, foi aprovada a Declaração Universal dos Direitos do Homem como marco desse processo. Tal declaração definiu "um padrão comum de realização para todos os povos e nações, os Direitos Humanos e liberdades fundamentais” (ALVES, 1994, p. 46). 
Efetivamente, portanto, a Declaração Universal dos Direitos do Homem produziu imediatos e incontestáveis resultados positivos de ordem prática na vida de todos os povos, tendo em vista, sobretudo, a multiplicação de Declarações, Tratados e Convenções posteriores a ela e, sem dúvida, ademais, pela influência exercida diretamente nas Constituições e no direito interno de muitos Estados.

Pérez Luño (2005, p. 27) traça uma distinção entre Direitos Humanos e Direitos Fundamentais. Para ele, resumidamente, pode-se dizer que Direitos Humanos são aqueles ínsitos a todas as pessoas, enquanto que os Direitos fundamentais são os Direitos Humanos positivados, ou seja, os direitos inerentes ao ser humano e escritos na Constituição. Para Bobbio (1992, p. 17) a grande parte das definições "são tautológicas". Veja-se: "Direitos do homem são os que cabem ao homem enquanto homem", ou "[...] direitos do homem são aqueles que pertencem, ou deveriam pertencer, a todos os homens, ou dos quais nenhum homem pode ser despojado”. Cita adiante outra definição do gênero: "[...] direitos do homem são aqueles cujo reconhecimento é condição necessária para o aperfeiçoamento da pessoa humana, ou para o desenvolvimento da civilização" (BOBBIO, 1992, p. 17).

Analisando outros conceitos a respeito do tema, tem-se a semelhança entre Direitos Humanos e direitos naturais, já que para os jusnaturalistas a teoria daqueles direitos seria um prolongamento dos direitos naturais. Enquanto que os positivistas negam tal relação e apregoam uma verdadeira ruptura entre os termos. A doutrina tradicional seguida, por exemplo, por Thomas Paine, considera que os Direitos Humanos são uma união entre os direitos naturais (que cada ser humano possui pelo simples fato de existir) e os direitos civis (aqueles que as pessoas possuem por viverem em sociedade) (PÉREZ LUÑO, 2005, p. 32).

Já Bobbio (1992, p. 16), nesse sentido, menciona que isso é uma ilusão dos jusnaturalistas "[...] que supunham ter colocado certos direitos (mas nem sempre os mesmos) acima da possibilidade de qualquer refutação, derivando-os diretamente da natureza do homem". Ilusão porque esta natureza é "[...] frágil como fundamento absoluto de direitos irresistíveis".

Ademais, Luño (2005) menciona a diferença entre Direitos Humanos e direitos subjetivos, já que estes podem desaparecer em razão da prescrição, por exemplo, enquanto que aqueles são inalienáveis e imprescritíveis. Cita a crise da teoria dos direitos subjetivos por guardar eterna relação com as novas condições econômicas que são imprescindíveis para o desenvolvimento do capitalismo. Pelas razões expostas ele também relata que o uso de outra expressão comumente utilizada, direitos individuais, deve ser igualmente rechaçada, já que conduz a um individualismo e as interações humanas requerem exigências sociais que são compatíveis com a sociedade atual.

Bobbio (1992, p. 19), por sua vez, expressa ainda a dificuldade de enfrentamento preciso do uso das definições "tautológicas" citadas acima, uma vez que existe uma dificuldade desconsiderada por muitos que é a "[...] ideologia assumida pelo intérprete”, já que o que é necessário para o "aperfeiçoamento da pessoa humana" requer uma interpretação de caráter subjetivo. Ademais, menciona que "[...] os Direitos Humanos constituem uma classe variável”, já que se modificam

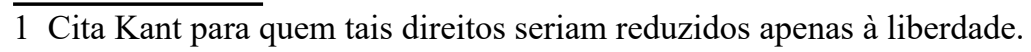


com as transformações históricas, o "[...] que prova que não existem direitos fundamentais por natureza”. Ressalta “[...] o que parece fundamental numa época histórica e numa determinada civilização não é fundamental em outras épocas e em outras culturas".

Sobre os direitos fundamentais, Bobbio (1992, p. 21) afirma que eles não são ilimitados, pois muitos entram em concorrência entre si o que os faz concluir de que os direitos têm eficácia diversa e, por isso, recebem fundamentos diferentes que nem sempre serão absolutos. Para exemplificar a questão, cita-se o exemplo mencionado pelo autor de que o direito a não ser escravizado e a não ser torturado implica automaticamente na exclusão do direito de possuir escravos. Não se pode, pois, afirmar um novo direito, sem suprimir ou relativizar algum outro já existente. Eles podem ser "fundamentais, sim, mas sujeitos a restrições - não podem ter um fundamento absoluto, que não permitisse dar uma justificação válida para a sua restrição".

A propósito, sobre a dificuldade de conceituação de Direitos Humanos, Fernández-Largo (2001, p. 19)

El conglomerado de exigências y enunciados jurídicos que denominamos como derechos humanos no es algo homogéneo ni inalterable históricamente, sino algo fluido y no expresado siempre en los mismos términos, ya que han sido encunciados desde una concepción política de la sociedad y de lo que es el derecho. No hay un concepción doctrinal que los prolonga. Por ello, no podemos contentarmos con buscar un término de común acepción para designarlos $[\ldots]^{2}$.

Nesse sentido, também é o posicionamento de Piovesan (2004, p. 46), quando diz que “[...] a definição de Direitos Humanos aponta uma pluralidade de significados" e que é justamente essa "pluralidade" que caracteriza a sua concepção contemporânea. Annoni (2008, p. 17) relata que há uma "[...] subjetividade impregnada na expressão Direitos Humanos" que "não pode ser medida". E, para tentar explicá-la "esbarra-se em novas questões [...] o que significa dizer 'inerentes ao ser humano'? ou: o que são direitos reconhecidos pela 'Lei Fundamental?' [...] quais são 'aqueles necessários ao desenvolvimento digno"”. Em resposta ela responde que eles “[...] são aqueles essenciais ao desenvolvimento digno da pessoa humana, que devem ser reconhecidos pela Lei Fundamental e garantidos pelo Estado dentro e fora de suas fronteiras".

Feito isso, passa-se para análise do acesso à terra enquanto direito humano, já que universalmente reconhecido na Declaração dos Direitos Humanos de 1948, o direito à toda pessoa individual ou coletivamente ao direito à propriedade. Isso está previsto no artigo 17 da referida declaração que, ressalta, ainda, que ninguém poderá ser arbitrariamente privado de sua propriedade.

Em âmbito interno, no Brasil, a Constituição da República Federativa do Brasil de 1988, trata do direito à propriedade como um direito e garantia individual. No artigo $5^{\circ}$, inciso XXII, assegura o "direito à propriedade", no XXIII, condicionando tal direito a sua função social. Especificamente, ao caso de aquisição de propriedades por estrangeiros, assegura no artigo 190,

2 Tradução livre: Um conjunto de enunciados e exigências legais que chamamos Direitos Humanos não é algo historicamente homogêneo e imutável, mas algo fluido e nem sempre expressa o mesmo significado desde uma visão política da sociedade, ou do que é o direito. Não há um conceito doutrinário que seja único. Portanto, não podemos nos contentar com um termo comum para designá-lo. 
que lei regulará e limitará a aquisição por pessoa física ou jurídica estrangeira (BRASIL, 1988).

Analisando as formas de aquisição de propriedades, tem-se que o colonialismo foi uma das características principais do século XVI, até os anos 50 e 60 do século XX. Ele é definido como "[...] um processo de ocupação de um país por estrangeiros, que estão decididos a incorporálo no seu próprio país, ou simplesmente a manter sua dominação indefinidamente" (SENGHOR, 1979, p. 9). O autor coloca que o colonialismo é “[...] pois a exploração de povos submetidos pelos seus conquistadores" (SENGHOR, 1979, p. 9).

O fato é que após os anos 40 mudou-se o centro da acumulação do capital, da empresa agrária para a empresa industrial. Nesse caso, o Estado criou novos mecanismos que levava a industrialização. Para Lopes (1981, p. 24) são dois processos os responsáveis por essa mudança. O primeiro, para a acumulação industrial associado ao desenvolvimento extensivo (agricultura de abastecimento urbano e os serviços), o segundo, com a acumulação de capitais centrada no centrosul.

A um outro nível pode-se definir o neocolonialismo como:

[...] fenômeno histórico caracterizado pelo domínio ou influência que as grandes potências exercem sobre os países descolonizados. Constitui uma manifestação nova de imperialismo, na medida em que um Estado tenta controlar os destinos de outro para assegurar a exploração de seus recursos econômicos e a sua fidelidade diplomática. (SENGHOR, 1979, p. 21)

Para este autor essa nova forma alcança dimensões universais após a segunda Guerra Mundial e se resume a dois traços essenciais, quais sejam, “[...] manutenção dos países de Terceiro Mundo como fornecedores de matérias-primas" e a "[...] luta pela hegemonia entre as grandes potências". (SENGHOR, 1979, p. 22). Mais adiante vai afirmar que ele vem sendo justificado com a ajuda que os países em vias de desenvolvimento necessitam para superar o atraso e as estruturas deficitárias deixados pelo colonizador.

De acordo com Ianni ${ }^{3}$ (1974, p. 85) os fatos mais recentes da história ecônomica do capitalismo mundial mostram que não "[...] é possível compreender como opera o imperialismo enquanto não se explica a vinculação do aparelho estatal do país subordinado às decisões, acordos e órgãos multilaterais, por meio dos quais boa parte das relações econômicas imperialistas se efetivam"4.

Portanto, percebe-se que a terra, nos últimos anos, foi transformada em mercadoria e que os arranjos jurídicos se transformaram. Na visão de Ianni (1979, p. 154) ela ganha uma nova roupagem social e outra dimensão histórica, na qual a propriedade legal predomina sobre a ocupação e a posse:

3 Relevante esclarecer, aqui, que o autor Otávio Ianni ainda é referência doutrinária quando se fala das questões de imperialismo, acesso à terra, globalização e colonialismo, embora seus escritos sejam dos anos 70. A sua sensibilidade crítica e aprofundamento teórico são "atemporâneos".

4 Alguns governos começaram a realizar nacionalizações de recursos minerais e empresas, bem como intensificaram a participação estatal nas atividades econômicas. Os mais importantes, citados por Ianni $(1974$, p. 89) foram Cárdenas, Vargas e Peron. 
Em pouco tempo, também a terra passa a ser mercadora, ganha preço; isto é, apropriada de modo privado e sob nenhuma outra forma. A terra passa a ser objeto e meio de produção de valores de troca. É inserida nas relações capitalistas de produção como um elemento das condições de produção controladas pela empresa privada. Pouco a pouco, ou se súbito, conforme o caso, a terra deixa de ser apenas, ou principalmente, objeto e meio de produção de valores de uso. O poder estatal aparece, de forma cada vez mais ostensiva e permanente, como um poder maior destinado a favorecer e acelerar o processo de privatização da terra, nos moldes exigidos pela empresa privada de grande porte, segundo a lógica de acumulação capitalista (IANNI, 1979, p. 154)

Nesse sentido, o autor relata que essa transformação não é pacífica, já que a metamorfose da terra envolve tanto a violência dos homens com a natureza quanto entre os homens entre si, já que essa expansão traz em si uma explosão de conflitos entre posseiros, fazendeiros e grileiros.

$\mathrm{Na}$ maioria dos casos a história mostra que tais conflitos foram compostos não só de fazendeiros e de grileiros, como também de empresas que realizavam aquisições de propriedades, inclusive estrangeiros, foco do presente trabalho. Assim, encontram-se registros da obra de Veloso (1968, p. 42) que no relatório de uma Comissão Parlamentar de Inquérito (CPI) de 1968, já se questionava sobre a venda de terras a estrangeiros. O deputado Haroldo Veloso nesse relatório descrevia as formas mais comuns de aquisição de propriedade, dizendo que normalmente havia a presença de um nacional para intermediar tal compra.

a) compra a antigos proprietários ou posseiros

Nestes processo, um intermediário entra, em contacto, com o proprietário ou posseiro de determinado lugar, de interesse de um grupo, e propõe a compra da mesma.

De um modo geral, o proprietário ou posseiro, sem recursos para explorar suas terras, com dificuldades em obter financiamento, e premido pelos impostos, principalmente os do IBRA, aceita com prazer a proposta, sempre feita com dinheiro à vista.

Este processo é repetido com todos os elementos da zona visada, que assim passa a ser propriedade de um grupo estrangeiro, apesar de muitas vezes, enquanto interessar, as terras ainda serem mantidas em nome dos antigos proprietários, o que dificulta em muito o levantamento de área do território nacional em mão de estrangeiros (VELOSO, 1968, p. 42)

Em ato contínuo, retrata como segunda forma comum a requisição de terras devolutas aos governos estaduais, em que um intermediário, nacional, com a conivência de funcionários dos departamentos de Terras requeria em nome de várias pessoas um grande lote de terras, de modo a adquirir toda uma zona cobiçada, que após a obtenção do título de propriedade, passavam por vendas reais ou simuladas as propriedades para pessoas ou grupos nacionais ou estrangeiros interessados na compra daquela área. Isso explica porque muitas terras devolutas passaram a se transformar em vários latinfúndios. A CPI exemplifica que esse processo foi largamento utilizado no Mato Grosso, Pará e Amazonas (VELOSO, 1968, p. 43). 
A terceira forma relatada por esse relatório é a grilagem. "Por intermédio deste processo, todos os tipos de fraudes são aplicados, desde escrituras falsificadas, aparentando documentos antigos, até títulos definitivos de compra de terras devolutas, também falsos" (VELOSO, 1968, p. 43)

Ianni $(1979$, p. 167) retrata que a grilagem é a forma mais importante das modalidades de aquisição de terras. "A grilagem atinge tanto as terras devolutas, isto é, do poder público, como terras ocupadas, nas quais posseiros recentes ou antigos têm a cultura efetiva e morada habitual". Para ele

Com frequência terras ocupadas são consideradas como devolutas, definição essa que permite aos grileiros e empresários, ou seus prepostos, classificar os posseiros como estranhos, recentes, invasores no lugar. Na grande maioria dos casos de grilagem, nos quais mesclam-se a falsificação de documentos, evidências e testemunhas com a violência privada, são os posseiros as vítimas principais (IANNI, 1979, p. 167)

Percebe-se dos relatos acima de que a grilagem é uma forma de aquisição que é articulada com os interesses do empresário, que é apoiado, muitas vezes, por interesses políticos e econômicos. Para Ianni, em suma, é violência. "Seja nos métodos - que podem, porém, ser extremamente sutis e, até 'legais' na aparência - seja nas consequências". Elas podem ser tanto no trabalhador ou no proprietário, nas migrações forçadas, espancamentos, prisões, etc. (IANNI, 1979, p. 172).

Nessa conjuntura, pode-se afirmar que todo processo histórico de aquisição de terras no Brasil foi um processo que sofreu contratempos, que revela uma estrutura de dependência como algo que define sua essência. Ianni (1974, p. 128) traz uma explicação interessante do porque que a dependência estrutural implica na formação de grupos sociais parasitários:

[...] a classe dominante, na sociedade dependente, parece sempre ambígua, ideologicamente descaracterizada, incapaz de formular projetos próprios além do nível conjuntural. Por isso que ela está sempre apta e disposta a submeter-se à liderança política, econômica, militar e intelectual dos governantes dos Estados Unidos. (IANNI, 1974, p. 128)

Segundo o autor, o problema é que os países da América Latina como um todo nunca conseguiram se libertar ou superar a " [...] contradição entre sociedade nacional, por um lado, e economia dependente, por outro" (IANNI, 1974, p. 128), sendo, por isso, instáveis, e, por vezes, ditatoriais sempre que se configura uma real possibilidade de mudança das estruturas de poder. Assim, a "[...] crescente transnacionalização da economia não só reorienta como reduz a capacidade decisória do governo nacional” (IANNI, 1997, p. 17).

A título de exemplo, vê-se o caso da Colombia em que Velasco (2013, p. 310-311) analisando o assunto sob a ótica de variáveis endógenas (gobierno corporativo, participación en bolsa de valores y capacidad de veto de compradores internacionales) e exógenas ("informalidad 
de la propiedad rural y tradición del inmueble”) na adoção de princípios, legitimidade e responsabilidade social na aquisição de terras por estrangeiros, concluiu o quanto esses fatores podem ser afetados e influenciados na promoção de direitos humanos. Cita-se o exemplo narrado de que quando não se impõe limites de tamanho e o perfil do adquirente, que isso pode acarretar a compra por pessoas oportunistas para uma venda posterior por um preço bem mais alto. Da mesma forma, quando a empresa não implementa um modelo de governo corporativo, ela não sente "aversão ao risco" por desrespeitar direitos humanos durante a sua prática de aquisição de terras.

Em praticamente todas as esferas da vida social e econômica há a influência e os estímulos das organizações internacionais e, é nesse contexto, que se deve entender o fenômeno do land grabbing, pois na medida em que se aprofundam as discussões fica claro que, conforme o nível de dependência estrutural, verifica-se uma complementação das sociedades capitalistas, já que em geral os processos econômicos e políticos que operam no centro do sistema capitalista têm uma força dominante. É o que se passa a discutir na sequência.

\section{O FENÔMENO DO LAND GRABBING: LIMITES E ALCANCE}

Tendo sido realizado os apontamentos iniciais a respeito da caracterização da evolução da aquisição do direito à propriedade, passa-se, especificamente a análise do fenômeno do lang grabbing. Antes de tudo, é preciso que se esclareça que o termo referido é conhecido no meio internacional como a aquisição de terras por estrangeiros nos países periféricos, especialmente, nos países latino-americanos e africanos. No Brasil, também, tem o sentido de grilagem de terras, mas via de regra, segue o primeiro significado.

A questão é, pois, o fato de diversas organizações, dentre elas o Banco Mundial (Bird), que tem admitido a grande demanda por terras e tem sido visto, nelas uma grande "oportunidade de negócios". Contudo, não se trata apenas de uma simples aquisição de terras por meio de contratos de compra e venda, mas sim aquilo que vem junto com as referidas aquisições, pois é preciso que sejam compreendidos os processos históricos que permeiam o acesso à terra, em especial na América Latina.

Castro e Igreja (2017, p. 167) ressaltam que de maneira geral, “[...] as corporações transnacionais (com origem nos Estados Unidos, Canadá, Espanha, Portugal, Itália e outros) são titulares de glebas ou de volumosos investimentos em terras na América Latina”.

Destacam, ainda que

A estrangeirização de terras na América Latina e Caribe é uma questão geopolítica. Para além da tradicional discussão sobre soberania nacional, coloca em evidência um fenômeno caracterizado por aquisições progressivas, baseadas na "apropriação do controle" das terras e territórios ("land grabbing") pelo capital internacional. Esse fenômeno não é inédito, mas sim um novo ciclo de expansão do capital, que 
tem resultado no aumento dos conflitos territoriais e fundiários e elevação dos preços das terras. Apesar de raízes coloniais, há aspectos de novidade, pois se descortinam a financeirização da terra, a valorização de glebas para a produção do complexo global de agrocombustíveis e outras nuances. (CASTRO; IGREJA, 2017, p. 167)

Apresentado o conceito, ainda que de forma breve, passa-se a desdobrar a previsão legal existente com o intuito de frear a aquisição de terras por estrangeiros no Brasil. Dessa forma, no Brasil, além do referido artigo 190 da CF, já se tinha a Lei no 5.709/71 que regulava e estabelecia os limites e os requisitos para a aquisição de imóveis rurais por estrangeiros. Foi promulgada no período ditatorial com o intuito de controlar e limitar a aquisição de terras por pessoas físicas ou jurídicas estrangeiras com ou sem residência ou sede no Brasil.

$\mathrm{O}$ art. $3^{\circ}$ da Lei $\mathrm{n}^{\mathrm{o}} 5.709 / 71^{5}$ traz que as pessoas físicas estrangeiras poderão adquirir imóveis de até três módulos de exploração sem a necessidade de autorização do INCRA (art. $7^{\circ}$, $\S 1^{\circ}$ do Decreto 74.695/74). Importante esclarecer que o módulo de exploração indefinido (MEI) mencionado no destacado artigo é fixado pelo INCRA, de acordo com critérios definidos em regulamento, para cada região específica do território nacional. A aquisição de três a cinquenta MEI necessita de uma autorização do INCRA para o devido procedimento de transmissão do imóvel (escritura e registro). Aliás, independentemente do tamanho do imóvel, se ele estiver em área de segurança nacional, além da referida autorização, será imprescindível a autorização do Conselho de Defesa Nacional (art. $7^{\circ}$, da lei $\mathrm{n}^{\mathrm{o}}$ 5.709/71). Por fim, sendo caso de compra ou arrendamento de área superior a cem MEI, é indispensável, ainda, a autorização do Congresso Nacional (art. 23, $\S 2^{\circ}$ da Lei $\left.n^{\circ} 8.629 / 93\right)$ (BRASIL, 1993).

Destaca-se que os mesmos limites são exigidos para a aquisição de terras por pessoas jurídicas estrangeiras, no entanto, é ainda preciso que ela detenha autorização para funcionamento no país. Se não houver tal autorização, não será possível a compra.

$\mathrm{O}$ art. 11 da referida Lei exige a comunicação trimestral ao INCRA e à Corregedoria de Justiça do respectivo Estado, de todos os imóveis rurais adquiridos por estrangeiros nesse período. Porém, ao que parece, em estudo preliminar, isso não foi regulado a contento. (BRASIL, 1971)

A Lei em comento (5709/71) limitou a aquisição de imóveis rurais por estrangeiros e empresas nacionais controladas por estrangeiros em $25 \%$ (vinte e cinco por cento) da superfície do município. Igualmente, a soma das áreas rurais pertencentes a pessoas estrangeiras, físicas ou jurídicas, não poderá ultrapassar a um quarto da superfície dos Municípios onde se situem e, as pessoas da mesma nacionalidade não poderão ser proprietárias, em cada Município, de mais de 40\% (quarenta por cento) da citada superfície a aquisição por pessoas de uma mesma nacionalidade, conforme dispõe o artigo 12 e os seus parágrafos. (BRASIL, 1971).

Ao revés, ficam excluídas dessa situação (artigo 12, §2 , da Lei 5709/71) os imóveis inferiores a 3 (três) módulos; aqueles que foram objeto de compra e venda, e/ou de promessa de

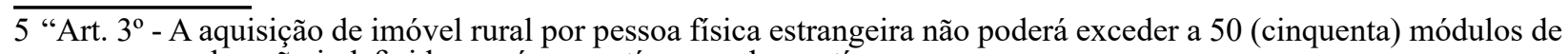
exploração indefinida, em área contínua ou descontínua. 
compra e venda cadastradas no INCRA em nome do promitente comprador, antes de 10 de março de 1969. Além disso, está excluído o caso de o adquirente ter filho brasileiro ou que seja casado com pessoa brasileira sob o regime de comunhão de bens. (BRASIL, 1971).

Outro ponto em destaque desta Lei é o fato de que o $\S 3^{\circ}$ do artigo 12, traz uma norma aberta e discricionária do que seria "prioritário", já que o Presidente da República “[...] poderá, mediante decreto, autorizar a aquisição além dos limites fixados neste artigo, quando se tratar de imóvel rural vinculado a projetos julgados prioritários em face dos planos de desenvolvimento do País". (BRASIL 1971)

Sauer (2010, p. 80) aponta a existência de divulgação de notícias e reportagens por jornais brasileiros que supostamente comprovam que várias dessas aquisições não são registradas de acordo com o comando legal acima descrito.

Ainda merece relevo a previsão de nulidade absoluta da transmissão de imóveis rurais a estrangeiros, sem a observância do previsto na lei em comento, conforme o artigo $15^{6}$. Desse modo, uma vez reconhecida a nulidade, via processo judicial, caberá ao estrangeiro adquirente buscar a reparação com a devida ação competente para reaver o montante pago pelo imóvel.

Assim, apresentadas as premissas que envolvem o tema, passa-se a análise das questões relativas aos direitos humanos como resposta contra hegemônica do poder de aquisição de terras e do desenvolvimento do capitalismo, no intuito maior de responder a problemática interposta.

\section{OS DIREITOS HUMANOS COMO RESPOSTA CONTRA-HEGEMÔNICA DO PODER DE AQUISIÇÃO DE TERRAS E DO DESENVOLVIMENTO DO CAPITALISMO}

Neste ínterim é importante apresentar os direitos humanos, outrora definidos no tópico inaugural como uma possível resposta aos conflitos de relacionamento e às múltiplas necessidades humanas, de forma a descrevê-los numa visão emancipatória de direitos, nas palavras de Wolkmer (2015, p. 257) “[...] numa dimensão de resistência, de liberação e de interculturalidade”. Em síntese, pretende-se debater os direitos humanos a partir de uma perspectiva local e intercultural, trazendo as lutas históricas sob a análise de um novo diálogo, tentando desconstruir o olhar eurocêntrico a eles apontados.

Já foi demonstrado que a internacionalização dos direitos humanos foi pensada de forma que trouxe uma certa harmonização dos interesses particulares de cada Estado, o que auxiliou justamente na construção de uma proteção e de uma teoria internacional dos direitos humanos

\footnotetext{
$\S 1^{\circ}$ - Quando se tratar de imóvel com área não superior a 3 (três) módulos, a aquisição será livre, independendo de qualquer autorização ou licença, ressalvadas as exigências gerais determinadas em lei.

$\S 2^{\circ}$ - O Poder Executivo baixará normas para a aquisição de área compreendida entre 3 (três) e 50 (cinquenta) módulos de exploração indefinida.

$\S 3^{\circ}$ - O Presidente da República, ouvido o Conselho de Segurança Nacional, poderá aumentar o limite fixado neste artigo". s

6 "Art. 15 - A aquisição de imóvel rural, que viole as prescrições desta Lei, é nula de pleno direito. O tabelião que lavrar a escritura e o oficial de registro que a transcrever responderão civilmente pelos danos que causarem aos contratantes, sem prejuízo da responsabilidade criminal por prevaricação ou falsidade ideológica. O alienante está obrigado a restituir ao adquirente o preço do imóvel".
} 
baseada no princípio da dignidade humana de uma forma universal. No entanto, em nome da soberania dos Estados e da autodeterminação dos povos alguns paradoxos foram estabelecidos, como por exemplo, a globalização e o pensamento neoliberal e, isso, algumas vezes passa a ser uma desculpa para legitimação de violações aos Direitos Humanos.

Para Wolkmer (2017, p. 288) “[...] por essas razões, os direitos humanos compreendidos na atual conjuntura eurocêntrica não possuem caráter universal e sim relativo, pois não alcançam todos os seres humanos [...]”. Em suas exatas palavras (WOLKMER, 2017, p. 289)

Não obstante, a maior questão que afronta o caráter universal dos direitos humanos são os efeitos da globalização e do pensamento neoliberal, a lógica de mercado atual, a atuação das empresas multinacionais, a posição das instituições financeiras, dentre outras, buscam um desenvolvimento estritamente econômico que não observa os direitos historicamente construídos para a proteção e bem estar do ser humano com uma vida digna.

Pode-se afirmar que a globalização acaba por sobrepor valores, haja vista que os interesses econômicos na maioria das vezes é maior do que a valorização e o culto aos direitos humanos. Isso, por si só, já leva ao repensar do Sistema Global de Proteção de Direitos Humanos. E, é nessa seara que se pode discutir uma abordagem latino-americana de maneira a não incentivar novas formas de colonização. "Na verdade, um pensamento contra-hegemônico de resistência que surja de espaços dependentes e sonegados torna-se manifestação apta a instrumentalizar a força de uma crítica inconformista e transgressora [...]" (WOLKMER, 2015, p. 245) justamente para colaborar no repensar de velhas formas de poder.

O contexto histórico eurocêntrico dos direitos humanos revela uma categoria de direitos liberal burguesa. Nesse cenário, direitos humanos são para os colonizadores e não para colonizados. Os Direitos Humanos foram fundados para o homem branco, europeu e burguês. Um discurso que contém em si uma ideologia da exclusão não pode servir para um sistema universal de direitos humanos. (WOLKMER; LIPPSTEIN, 2017, p. 297)

Assim, o pensamento crítico recebe a grande função de revelar a conscientização daquilo que foi posto como uma verdade universal. E, no que tange ao presente trabalho, quer-se verificar se a possibilidade do land grabbing constituir-se, ou não, em uma nova forma de pensamento subalterno. É preciso, pois, resgatar

[...] a razão de ser de uma forma teórica e prática de Direito mais comprometida com os processos de descolonização de sociedades como a latino-americana está na transgressão ao convencional instituído e injusto, na possibilidade de se revelar como recurso estratégico de resistência às diversas modalidades de colonialismos (acadêmico, cultural e institucional) e de contribuir, responsavelmente, para a construção criativa e empírica de uma sociedade mais comprometida com valores nascidos de práticas sociais emancipadoras. (WOLKMER, 2015, p. 254-255) 
É certo que ao analisar o caso do presente artigo, o que chama a atenção é o fato de na América-latina haver um grande número de situações de estrangeirização de terras sejam privadas, sejam de espaços de usos coletivos ou de povos tradicionais. "Os territórios dos indígenas e dos pastores, por exemplo, são frequentemente enquadrados na polêmica definição de áreas subutilizadas ou improdutivas" (CASTRO; IGREJA, 2017, p. 167). Salientam os autores que tal identificação e mapeamento são realizados por “[...] levantamentos estatísticos, cartográficos e imagens de satélite que capturam as características físicas, mas não as relações sociais que ocorrem nesses espaços”. Portanto, resgatando uma visão muito rasa dos verdadeiros valores envolvidos, considerando "[...] a terra e a propriedade como 'coisas' desprovidas de dimensão social”' e, por outro lado, vendendo uma visão de que o uso intensivo das terras é sinônimo de progresso e desenvolvimento.

Além disso, a estrangeirização de terras, como já dito anteriormente, se coloca como questão geopolítica que ultrapassa não só os riscos à soberania nacional, mas que põe em destaque um fenômeno caracterizado por "[...] aquisições progressivas, que avançam sobre biomas estratégicos, como Cerrado e Amazônia, relacionando-se com a cultura de commodities e repercutindo, diretamente, no aumento do preço das glebas e no encarecimento das políticas públicas de acesso à terra" (CASTRO; IGREJA, 2017, p. 168)

Wolkmer e Lippstein (2017, p. 298) afirmam

Nesse sentido, pode-se vislumbrar, a partir da literatura intelectual latinoamericana e de alguns adeptos europeus à esta corrente, que as formas hegemônicas e monoculturais do saber possuem por objetivo final o monopólio do poder como instrumento para a exploração. A importação de ideologias, filosofias e modos de saber são práticas de colonização com outras roupagens das que praticadas no período imperial, mas mesmo assim com finalidades de dominação semelhantes. Essa forma de percepção ocorre com a compreensão dos Direitos Humanos enquanto única visão legítima, a visão eurocêntrica como uma verdade universal.

Desse modo, já é passada a hora de se questionar se a permissão da estrangeirização não constitui, de fato, uma nova forma de colonialismo, pelos argumentos expostos por Wolkmer? É de relembrar que este autor há tempos defende um pluralismo jurídico e uma teoria crítica do direito que para ele se refere a um "[...] profundo exercício reflexivo de questionar o que se encontra normatizado e oficialmente consagrado (no plano do conhecimento, do discurso e do comportamento) em uma determinada formação social [...]", bem como argumenta "[...] a possibilidade de conceber outras formas não alienantes, diferenciadas e pluralistas da prática jurídica" (WOLKMER, 2003, p. 13-14).

Rubio (2013, p. 57) analisando a ideia de Wolkmer diz que o pluralismo jurídico liberal burguês de outrora (século XX) está sendo novamente introduzido na sociedade capitalista como uma nova tática. Segundo ele as principais tendências são:

[...] a descentralização administrativa, a integração dos mercados, a globalização 
e a acumulação flexível do capital, a formação de blocos econômicos, as políticas de privatização e de ajuste estrutural, o direcionamento informal dos serviços e da regularização social supranacional.

Concretamente, percebe-se que o autor (Rubio descrevendo a teoria de Wolkmer) não quer contrariar o Estado, mas quer questionar "[...] principalmente de sua não observação e, especialmente nas sociedades periféricas, para a sua insuficiência e, em não raras vezes, pela sua ausência" (RUBIO, 2013, p. 60). Sua crítica mais veemente é contra o formalismo ditado e defendido de forma absoluta "[....] sem considerar o contexto social, econômico e cultural a que se encontram" (RUBIO, 2013, p. 60).

Então, retomando o questionamento proposto, percebe-se que a estrangeirização de terras nacionais pode ser considerada uma nova forma de colonização. Da maneira como está posta a compra de terras por estrangeiros, é possível que ocorram problemas quanto à soberania e um consequente aumento na desigualdade social, por limitar o acesso de produtores brasileiros aos imóveis rurais, haja vista a previsão expressa do artigo 190 da CF/88 e a falta de fiscalização dos instrumentos previstos pela Lei 5.709/71 idealizada em outra realidade social.

Já foi apresentado acima que os cartórios de registros de imóveis podem negar o acesso de estrangeiros a aquisição de títulos e que a Lei em comento trouxe o reconhecimento da nulidade da transação caso os requisitos legais não estejam presentes. O grande problema é que ela - lei - precisa ser atualizada as atuais conjunturas sociais e econômicas e, que os próprios defensores confundem-se em orientações. Basta lembrar que em 1998 a Advocacia-Geral da União (AGU) interpretou que empresas nacionais e estrangeiras não poderiam ser tratadas de maneira diferente, liberando a compra. O jornal Estadão, por meio de seus responsáveis Borges e Castro (2017) divulgou o alerta:

Em 2010, por exemplo, o Chongqing Grain Group, da China, anunciou a disposição de aplicar US\$ 300 milhões na compra de 100 mil hectares no oeste da Bahia, para produzir soja. Em alguns setores, a crítica era de que negócios desse tipo envolvem o controle de grandes áreas por grupos subordinados à estratégia de uma potência estrangeira, que poderia nem sempre seguir a lógica do Estado brasileiro.

Diante disso um novo parecer da AGU restabeleceu as restrições para esse tipo de aquisição, proibindo que grupos internacionais obtenham o controle de propriedades agrícolas. Em 2012, o Projeto de Lei $4059^{7}$ foi apresentado no Congresso modificando a restrição. Hoje, encontra-se em apenso ao Projeto de Lei 2289/2007, tendo como última atividade legislativa em 16/09/2015 em que se aprovou regime de urgência para o seu trâmite ${ }^{8}$. De lá para cá, pode-se

7 Esta Lei regulamenta o art. 190 da Constituição Federal, altera o art. $1^{\circ}$ da Lei no ${ }^{\circ}$ 4.131, de 3 de setembro de 1962 , o art. $1^{\circ}$ da Lei $n^{\circ} 5.868$, de 12 de dezembro de 1972 e o art. $6^{\circ}$ da Lei $n^{\circ} 9.393$, de 19 de dezembro de 1996 e fixa outras providências, com o objetivo de disciplinar a aquisição, o arrendamento e o cadastro de imóvel rural em todo o território nacional por pessoas físicas e jurídicas estrangeiras, sendo estas aquelas constituídas e estabelecidas fora do território nacional.

8 Dados atualizados até o dia 07 de abril de 2018 com pesquisa no site da Câmara. Disponível em: http://www. 
visualizar que o mesmo entrou por diversas vezes em pauta, porém nunca foi apreciado, sendo arquivado e desarquivado com o passar do tempo. No momento, a situação atual é de espera pela criação de Comissão Temporária pela Mesa da Câmara9 .

Em síntese, no Brasil, as pessoas jurídicas podem adquirir até 3 módulos rurais de forma livre, sem necessidade de autorização, enquanto que as pessoas físicas ficam dispensadas de tal autorização até 20 módulos rurais. Nos demais casos, tem-se restrições à aquisição de terras por estrangeiros. Pelo Projeto de Lei 4059/12, não poderão comprar terras rurais no Brasil, ainda que indiretamente: fundos soberanos constituídos por outros países; organizações não governamentais ou fundações particulares com sede no exterior, sendo proibido, ademais o arrendamento de imóvel rural a estrangeiros e a venda ou doação a estrangeiros de terras da União, dos estados ou dos municípios. O que chama atenção é que continuam autorizadas a comprar imóveis rurais companhias de capital aberto, cuja consequência prática, é de que o investidor estrangeiro, sob a forma de uma empresa nacional de capital estrangeiro, terá o mesmo tratamento que uma empresa brasileira (SOUZA, 2016).

Percebe-se que a situação ainda não foi modificada. Encontram-se especulações de substitutos ao referido projeto, mas nada de concreto. Zaia (2017) trouxe a notícia de que a Casa Civil havia finalizado um projeto de lei que liberaria a compra e o arrendamento de terras por empresas com controle estrangeiro, “[...] sem estipular limite de área como sempre defenderam o setor florestal e a bancada ruralista no Congresso". No entanto, a proposta também traria a proibição a empresas e/ou cidadãos estrangeiros que "[...] detenham ou arrendem, juntos, mais do que $25 \%$ do território de um município", proibindo, ademais que "[...] companhias ou pessoas estrangeiras da mesma nacionalidade sejam proprietárias de terras que somem mais de $40 \%$ do território de uma cidade" (ZAIA, 2017).

Alfonsin (2016), analisando os projetos de lei em comento diz que se forem aprovados serão um “[...] esbulho territorial incentivado por outros países [...]; “[...] são colonialistas e realizam o crime de lesa-pátria, por desvelar a traição e o roubo da soberania [...]”, criticando igualmente que os grupos transnacionais escondem os seus efeitos sociais e ambientais, denotando, na prática, que o poder econômico estará acima da legislação brasileira.

Enquanto isso, as tradings internacionais vêm dominando, ao longo dos últimos anos a produção de grãos no Brasil, sem qualquer entrave ou monitoramento de suas atuações. Basta ver as atuações da sul-coreana CJ CheilJedang e da chinesa Cofco International que negociam commodities no Brasil há anos. Elas compram, armazenam, transportam, negociam e processam alimentos como milho, soja e trigo, dentre outros. Outras vezes, utilizam-se de cédula de produto rural, que vincula o financiamento à entrega ao credor da produção futura dos produtores rurais, justamente para garantir esse controle (FREITAS, 2017) ${ }^{10}$.

camara.gov.br/proposicoesWeb/fichadetramitacao?idProposicao $=548018$.

9 Dados atualizados em 08 de maio de 2020. Disponível em: https://www.camara.leg.br/proposicoesWeb/ fichadetramitacao?idProposicao=373948. Acesso em: 08 maio 2020.

10 Cita-se, ademais ACJ, que tem sede em Seul, espera duplicar o volume negociado de grãos para 20 milhões de toneladas no médio e longo prazos de 10 milhões de toneladas esperados para a safra 2017-2018. Na safra 20162017, a empresa vendeu cerca de 6 milhões a 8 milhões de toneladas. Todo o volume foi destinado à Ásia e cerca de metade foi produzida no Brasil. (FREITAS, 2017) 
De acordo com Pinto Neto (2017, p. 66)

\begin{abstract}
Percebe-se que a presença estrangeira no início do século XXI traz especificidades, que são relevantes e não podem ser ignoradas. Através da apresentação do estado da arte das pesquisas sobre a estrangeirização de terras, contata-se que o fenômeno tem a relevância, pois causa e acirra uma série de impactos aos sujeitos coletivos de direito do campo - como ampliação da desterritorialização do campesinato e o aumento no preço das terras-, e à sociedade de modo geral, como a ameaça a soberania alimentar e territorial.
\end{abstract}

Vê-se, pois, que a presença estrangeira no Brasil é historicamente construída sob o viés exploratório e, dessa forma constitui-se enquanto elemento da própria formação histórica e cultural do país. No entanto, é um “[...] processo que exige maiores reflexões sobre a construção de mercados globalizados que impactam o campo, na concentração de terras e no acirramento das disputas territoriais feitas de forma global”. (PINTO NETO, 2017, p. 66)

É importante, pois, nesse cenário, aplicabilidade do reconhecimento dos direitos humanos de uma forma pluralista e emancipadora, como aduz Wolkmer, para que se possa reconhecer, de fato, os direitos humanos e fundamentais de acesso à propriedade e a sua garantia com dignidade, e respeito à soberania nacional.

De acordo com Wolkmer (2013, p. 41)

Diante do declínio das práticas tradicionais de representação política, da escassa eficácia das estruturas judiciais e estatais em responder à pluralidade de demandas e conflitos, do crescente aumento de bolsões de miséria e das novas relações colonizadoras de países ricos com nações em desenvolvimento, abrese a discussão para a consciente busca de alternativas capazes de desencadear diretrizes, práticas e regulações voltadas para o reconhecimento à diferença (singular e coletiva) de uma vida humana com maior identidade, autonomia e dignidade.

Para tanto, o aporte teórico de Wolkmer aponta o uso de cinco campos de efetividade, a saber: emergência de novos sujeitos coletivos e a satisfação de necessidades humanas fundamentais, reordenação política do espaço público, a ética da alteridade e os valores universais dos processos de racionalização.

No que tange aos novos sujeitos coletivos, o autor menciona os denominados novos movimentos sociais, que na visão de Gohn (2013, p. 14) "[...] representam forças sociais organizadas que aglutinam as pessoas não como força-tarefa, de ordem numérica, mas como campo de atividade e de experimentação social, e essas atividades são fontes geradoras de criatividade e inovações socioculturais". Wolkmer (1994, p. 210) põe em relevo a característica de sujeitos ativos, atuantes, participativos, autônomos, de maneira que suas atuações contribuam para um ambiente democrático e participativo. Naturalmente para o tema em questão poder-se-ia citar o despertar dos próprios produtores rurais, os congressistas que defendem a causa e, até mesmo, as 
organizações não governamentais, de modo a fazer respeitar o interesse do grupo e o respeito aos direitos humanos e fundamentais.

Sobre o segundo ponto, qual seja, a satisfação de necessidades humanas fundamentais, o autor (WOLKMER, 1994, p. 216) apresenta o ideal de que o ordenamento jurídico deve fazer a regulamentação e, refrear o impulso que envolve as intenções de aquisições de bens. Inclui dentro desse conceito de necessidades àquelas sociais, materiais, existenciais de vida, meios de subsistência, culturais, dentre outras, argumentando que toda nova história nasce de uma sociedade insatisfeita elaborada pelas interações dos indivíduos. Vê-se, nesse caso, o aumento crescente da exploração por Empresas Tradings que têm o papel de intermediar a negociação entre produtores e compradores nacionais e internacionais, muitas vezes, deixando o produtor em condições de não negociar em razão das artimanhas de entrega e captação do produto, como já referido acima.

Quanto à reordenação política do espaço público, Rubio (2013, p. 63) analisando a obra de Wolkmer aponta que, na visão deste, o caminho seria a democracia, a descentralização e a participação. "A liberdade não há que ser limitada, mas potencializada. É uma herança ilustrada que está presente. O direito a ter direitos e a possibilidade de desfrutá-los necessita do apoio de um processo democrático e participativo [...]". Nessa luta de acesso à terra, visualizam-se inúmeros casos de violência e abuso no campo ${ }^{11}$, muitos com grande destaque internacional, como o caso Chico Mendes, o massacre de Eldorado dos Carajás, o assassinato da irmã Dorothy Stang, dentre outros $^{12}$.

Com propriedade escreve Reis (2012)

A história da formulação da terra como um direito humano é muito rica, pois se parte de uma interpretação marxista da realidade e de uma visão religiosa da relação entre homem e terra e, a partir da experiência dos movimentos sociais na demanda por terras e das alianças forjadas com redes transnacionais e organizações internacionais, se constrói não só a demanda por um novo direito humano, mas também por uma reinterpretação dos direitos humanos como um todo, tendo por base uma crítica do individualismo.

A luta não é fácil e muito há de ser feito no que tange aos processos de regularização fundiária no Brasil e do direito humano do acesso à terra e a moradia, mas fica a esperança de que a melhor regulamentação da aquisição de terras por pessoas e empresas estrangeiras já seja um pequeno passo para evitar os casos de grilagem, de land grabbing e de abusos contra os possuidores.

O quarto elemento citado por Wolkmer (2015, p. 211) diz respeito a ética da alteridade,

$11 \quad$ Entre 1997 e 2009, do total de 42 denúncias consideradas admissíveis de acordo com os relatórios anuais da $\mathrm{CIDH}$, dezesseis estavam diretamente relacionadas à questão da terra e à violência no campo: assassinatos de líderes sindicais rurais, assassinatos em evacuação de terras, grampos nos telefones de lideranças rurais, grilagem, invasão de terras indígenas, desrespeito a terras quilombolas e uma referente à guerrilha do Araguaia. Nas decisões de mérito publicadas ao longo desse período, assim como no acordo amigável referente a denúncias de trabalho escravo, o órgão reconheceu a responsabilidade do Estado brasileiro nas violações, recomendou ao Brasil investimentos na investigação, punição e indenização das vítimas e suas famílias, além de ressaltar a importância da busca de mecanismos pacíficos de solução para o problema de terra e de medidas visando maior eficiência na atuação das forças policiais e do Judiciário. (REIS, 2012).

12 Mais recentemente o termo é utilizado nas acusações contra Bernardo de Mello Paz o idealizador do Instituto Inhotim, maior museu a céu aberto da América Latina, como um dos crimes por ele cometidos. (LARA, 2018) 
com base nos pensamentos de Dussel. Cita que ela é uma "[...] ética antropológica da solidariedade, que parte das necessidades dos segmentos humanos marginalizados e se propõe a gerar uma prática pedagógica libertadora, capaz de emancipar os sujeitos históricos oprimidos, injustiçados, expropriados e excluídos". E, segue o autor, escrevendo que

[...] por ter de refletir os valores emancipatórios de novas identidades coletivas que vão afirmando e expressando uma práxis concreta comprometida com a dignidade do 'outro', encontra seus subsídios teóricos não só nas práticas sociais cotidianas e nas necessidades reais, mas igualmente em seus pressupostos epistemológicos da chamada vertente latino-americana da "filosofia da Libertação". (WOLKMER, 2015, p. 211)

Aliás, é importante concebê-la não apenas em uma perspectiva individualista, do simples ver-se no "outro", mas de ver o "outro" na sua essência, com todas as suas distinções e, mesmo assim, manter o respeito e a aceitação de suas diferenças. Derrida (1994, p. 51), expressa que “[...] não há diferença sem alteridade, não há alteridade sem singularidade, não há singularidade sem aqui-e-agora". No mesmo sentido, Pereira (2010, p. 18) fala que "[...] o reconhecimento da diferença é a condição fundamental para o rompimento do caráter apropriativo da racionalidade que tende a reduzir o outro ao mesmo, padronizando, igualizando", isto é, "[...] toda essa combustão de opostos traz a complexidade da violência ao mundo moderno. Existe uma relação simétrica entre a violência e o encobrimento da alteridade" (PEREIRA, 2010, p. 18). Assim, vê-se que tais apontamentos são essenciais para a compreensão de alteridade e para o enfrentamento do problema que norteia a presente pesquisa, pois não se está a renunciar os preceitos universais, mas acredita-se veementemente que é preciso reafirmar a historicidade do tema no Brasil, de modo a se redefinir novos valores.

O último ponto necessário para Wolkmer, enquanto ideia emancipadora, aduz que a realidade da vida constitui o ponto concreto de partida, pois da conflituosidade do dia-a-dia nascem pluralidades de ações humanas que requerem interação e participação dos cidadãos e dos novos movimentos sociais, como dito alhures.

O grau de significação não está somente na competência do discurso crítico que dessacraliza o formalismo instrumental normativista, por demais comprometido com os mitos ideológicos e com as relações de colonialidade de poder, mas, igualmente, no compromisso pedagógico da "crítica jurídica" com a criação de um espaço alternativo de mudanças, delineado pela discussão e pela participação, gerador de um Direito verdadeiramente justo. (WOLKMER, 2015, p. 273)

Nesse sentir, Castilho (2018, p. 173) ressalta que a "[...] crítica aos processos políticos, culturais e intelectuais que encobrem os mecanismos desiguais de construção do valor social condiz com o desvelamento da proposta do pensamento descolonial". Por isso, Herrera Flores (2009, p. 229-230) trabalha com a proposta de que o único caráter universalizante para o discurso de direitos humanos é a capacidade criativa e a forma de se recriar mundos e ações condizentes da 
vida com dignidade. Em suas palavras:

E, ao final, confluímos num conceito que podemos resumir na seguinte frase: os direitos humanos são o conjunto de processos pela luta pela dignidade humana. Dignidade que se baseia mais no valor de uso (necessidades e capacidades de fazer) que no valor de troca (expectativas contínuas de acumulação). Dignidade que se baseia na luta contra o acesso desigual aos bens que veio imposta pelos processos de divisão capitalista do fazer.

De acordo com sua literatura Castilho (2018, p. 238) resume que "[...] o acesso à terra ou à moradia não pode ser reduzido à forma de satisfação dominante e juridicamente sancionada pelo direito positivo convencionalmente promulgado". Assim, a proposição de uma teoria crítica dos direitos humanos revela consigo a "[...] importância de uma construção de um multiculturalismo crítico que supere as políticas de discriminação positiva que, quando absolutizadas, patologizam o diferente e o obrigam a aceitar acriticamente o padrão universal” (CASTILHO, 2018, p. 260).

Ainda que se admitam, pois, a venda de terra para pessoas e empresas estrangeiras, não se pode mais negar o caráter crescente que o tema suscita no que tange à perda de soberania e a influência de tradings estrangeiras no Brasil. Conquanto, torna-se imprescindível um novo projeto de Lei ético e libertador, viabilizando, de fato, o acesso à terra como um direito humano, com visão descolonial e com uma perspectiva crítica, anti-imperialista e repleta de caráter transformador.

Ao que se percebe na visão de Galeano (2018, p. 18):

É a América Latina, a região das veias abertas. Do descobrimento aos nossos dias, tudo sempre se transformou em capital europeu ou, mais tarde, norteamericano, e como tal se acumulou e se acumula nos distantes centros do poder. Tudo, a terra, seus frutos e suas profundezas ricas em minerais, os homens e sua capacidade de trabalho e de consumo, os recursos naturais e os recursos humanos. O modo de produção e a estrutura de classes de cada lugar foram sucessivamente determinados, do exterior, por sua incorporação à engrenagem universal do capitalismo.

Para ele, pois, o atraso e a miséria da América Latina são o resultado do seu fracasso já que se especializou em perder recursos naturais. Mas, por outro lado, revela que o campo “[...] não é tão só uma sementeira de pobreza: é também uma sementeira de rebeliões, embora as agudas tensões sociais amiúde se ocultem, as mascaradas pela aparente resignação das massas". (GALEANO, 2018, p. 183)

Portanto, parece, num primeiro nível, que as reivindicações realizadas contribuem para o processo da estrangeirização de terras no Brasil e que os representantes do setor do agronegócio tendem a atuar de forma ilegítima, já que não congregam aquelas solicitações realizadas pelos movimentos sociais, buscando alterar a legislação sem garantir direitos de fato. Por isso, é urgente o reconhecimento dos direitos humanos enquanto crítica emancipadora, eis que o assunto gera impactos na soberania alimentar, no aumento do preço das terras, na expansão das fronteiras 
agrícolas e na concentração de terras, dentre outros fatos que ainda merecem discussão ao nível de conclusão.

\section{CONCLUSÃO}

Diante do exposto até então, é possível constatar que o mundo hodierno ostenta uma dicotomia em que, ao passo que há grandiosa evolução nas tecnologias, na veiculação e disseminação de informações e nos bens de serviço, ainda existem pessoas em situações degradantes de violações maciças a direitos humanos básicos, geradas por intolerância, por violência, pelo preconceito, pela falta de empatia e pela busca incessante do lucro.

O tema apresentado foi demarcado ao longo de três pontos durante os quais a necessidade da difusão dos direitos humanos assumiu diversos contornos. Nesse sentido, os apontamentos iniciais prestaram-se a descrever a luta pela terra como direito humano no Brasil, momento em que se analisaram as formas de aquisição de terras pelos estrangeiros. Demonstrou-se que o fenômeno do colonialismo no continente latino-americano, em especial, no Brasil, foi construído sob a base do abuso e da selvageria social. Após, apresentou-se o fenômeno do land grabbing, seus limites e seu alcance.

Ao final e, em resposta ao questionamento proposto, descreveu-se os direitos humanos como resposta contra hegemônica do poder de aquisição de terras e do desenvolvimento do capitalismo na sua perspectiva crítica e pluralista. Desse modo, o fenômeno da estrangeirização de terras não pode ser enquadrado como um novo fato da questão agrária, uma vez que investimentos e apropriação de terras por pessoas estrangeiras decorre do próprio processo de colonização. No entanto, a forma com ele tem se dado, despertando interesses internacionais, tem contribuído para a maior dependência econômica do Brasil às potências internacionais, seja pelas permissões de monopólios de exploração, seja pelo aumento da terra, seja, ainda, pela exploração dos campesinos vulneráveis.

Portanto, o fenômeno do land grabbing pode sim ser visto não só como uma nova forma de violação dos direitos humanos, mas também de uma nova forma de colonialismo ou de neocolonialismo, já que muitas vezes tratam de casos em que posseiros habitantes dos locais há décadas são retirados para dar lugar aos estrangeiros, sem falar nos problemas ambientais, na busca incessante por água e, pelo descaso do INCRA que sequer possui controle e dados atualizados sobre a quantidade de estrangeiros nessa condição, o que contribui sobremaneira, inclusive, para o desrespeito à soberania nacional.

Por isso, percebe-se a premente urgência de se trabalhar com outras vias, outros paradigmas, como por exemplo, o constitucionalismo latino-americano, pois entende-se que land grabbing assume, na atualidade, o papel de uma nova forma de colonialismo. Assim sendo, os pressupostos de interculturalidade e pluralismo, presentes no constitucionalismo latino-americano pode fazer frente a essa devasta realizada, uma vez que trabalha com o pressuposto de valorização 
do ser, do respeito à cultura e ao local e da responsabilização social.

\section{REFERÊNCIAS}

ALFONSIN, Jacques. O Brasil roubado por latifundiários. In: Combate Racismo Ambiental, 29 fev. 2016. Disponível em: https://racismoambiental.net.br/2016/02/29/o-brasil-roubado-porlatifundiarios-vem-ai-mais-um-crime-desse-tipo-por-jacques-tavora-alfonsin/. Acesso em: $21 \mathrm{abr}$. 2018.

ALVES, José Augusto Lindrgen. Os direitos humanos como tema global. São Paulo: Perspectiva, 1994.

ANNONI, Danielle. Perspectiva histórica dos direitos humanos e os novos direitos. In: SILVA, Reinaldo Pereira e (Coord.) Novos direitos: conquistas e desafios. Curitiba: Juruá, 2008.

BOBBIO, Norberto. Era dos direitos. Rio de Janeiro: Campus, 1992.

BORGES, André; CASTRO, Fabrício de. Governo finaliza projeto que libera a venda de terras a estrangeiros. In: Estadão, São Paulo, 17 de fev. 2017. Economia \& Negócios. Disponível em: http://economia.estadao.com.br/noticias/geral,governo-finaliza-projeto-que-libera-a-venda-deterras-a-estrangeiros,70001669078. Acesso em: 05 mai 2018.

BRASIL, Constituição (1988). Constituição da República Federativa do Brasil. Brasília, DF: Senado Federal: Centro Gráfico, 1988.

BRASIL. Lei n 5.709, de 7 de outubro de 1971. Regula a Aquisição de Imóvel Rural por Estrangeiro Residente no País ou Pessoa Jurídica Estrangeira Autorizada a Funcionar no Brasil, e dá outras Providências. Diário Oficial [da] República Federativa do Brasil, Brasília, DF, 11 out. 1971. Disponível em: http://www.planalto.gov.br/ccivil_03/leis/L5709.htm Acesso em: 13 out. 2017.

BRASIL. Lei no 8.629, de 25 de fevereiro de 1993. Dispõe sobre a regulamentação dos dispositivos constitucionais relativos à reforma agrária, previstos no Capítulo III, Título VII, da Constituição Federal. Diário Oficial [da] República Federativa do Brasil, Brasília, DF, 25 fev. 1993. Disponível em: http://www.planalto.gov.br/ccivil_03/leis/L8629.htm. Acesso em 14 out. 2017.

CASTILHO, Natália Martinuzzi. Reinventando os direitos humanos a partir do Sul: Herrera Flores e a crítica descolonial. Rio de Janeiro: Lumen Juris, 2018.

CASTRO, Luís Felipe Perdigão de; IGREJA, Rebecca Lemos. Estrangeirização de terras na perspectiva das formas de colonialidade no agro latino-americano. Revista de Estudos e Pesquisas sobre as Américas, Brasília, v. 11, n. 2, p. 164-179. Disponível em: http://periodicos. unb.br/index.php/repam/article/view/24798. Acesso em: 12 out. 2017. 
DERRIDA, Jacques. Espectros de Marx: o estado da dívida, o trabalho do luto e a nova Internacional. Rio de Janeiro: Relume, 1994.

FERNÁNDEZ-LARGO, Antonio Osuna. Teoría de los derechos humanos: conocer para practicar. San Esteban: Edibesa, 2001.

FREITAS, Tatiana. Trading coreana enfrenta gigantes agrícolas no Brasil. UOL. 5 out. 2017. Economia. Disponível em: https:/economia.uol.com.br/noticias/bloomberg/2017/10/05/tradingcoreana-enfrenta-gigantes-agricolas-no-brasil.htm. Acesso em 07 abr. 2018.

GALEANO, Eduardo. As veias abertas da América Latina. Porto Alegre: L\&PM POCKET, 2018.

GOHN, Maria da Gloria. Movimentos sociais no início do século XXI: antigos e novos atores sociais. Rio de Janeiro: Vozes, 2013.

GOTTI, Alessandra Passos; RICARDO, Carolina de Mattos. Direitos humanos como sustentáculo do Mercosul. In: PIOVESAN, Flávia. (coord.). Direitos humanos, globalização econômica e integração regional: desafios do direito constitucional internacional. São Paulo: Max Limonad, 2002. p. 307-334.

HERRERA FLORES, Joaquim. Teoria Crítica dos Direitos Humanos. Os direitos humanos como produtos culturais. Rio de Janeiro: Lumen Juris, 2009.

IANNI, Octavio. A política mudou de lugar. In: DOWBOR, Lalislau; IANNI, Otavio; RESENDE, Paulo Edgar A. Desafios da globalização. Rio de Janeiro: Vozes, 1997, p. 17-27.

IANNI, Octávio. Imperialismo na América Latina. Rio de Janeiro: Civilização Brasileira, 1974.

IANNI, Octávio. A luta pela terra: história social da terra e da luta pela terra numa área da Amazônia. Petrópolis: Vozes, 1979.

LARA, Bruna de. De grilagem a trabalho infantil: surgem novos crimes de Bernardo paz, idealizador do Inhotim. THE INTERCEPT BRASIL. 8 de jul. 2018. Disponível em: https:// theintercept.com/2018/06/08/crimes-bernardo-paz-do-inhotim/. Acesso em: 10 jun. 2018.

LOPES, Juarez Rubens Bramdão. Do latifúndio à empresa: Unidade e diversidade do capitalismo no campo. São Paulo: Vozes, 1981.

PINTO NETO, Geraldo Miranda. A solução é alugar o brasil? um estudo da atuação dos representantes do agronegócio na disputa normativa sobre a estrangeirização de terras no Brasil. 2017. 152 f. Dissertação (Mestrado em Direito) - Universidade de Brasília, Brasília. 2017.

PEREIRA, Gustavo Oliveira de Lima. Direitos humanos e transnacionalização: a questão dos apátridas pelo olhar da alteridade. 2010. In: REUNIÃO DO GRUPO DE ESTUDOS SOBRE INTERNACIONALIZAÇÃO DO DIREITO E JUSTIÇA DE TRANSIÇÃO (IDEJUST), 2, 
2010, São Paulo. Anais [...]. São Paulo: IRI/USP, 2010. Disponível em: https://idejust.files. wordpress.com/2010/04/ii-idejust-pereira.pdf. Acesso em: 09 de abr 2018.

\section{PÉREZ LUÑO, Antonio-Enrique Pérez. Derechos humanos, estado de derecho y} constitución. 9. ed. Madri: Editorial Tecnos, 2005.

PIOVESAN, Flávia. A universalidade e a indivisibilidade dos direitos humanos: desafios e perspectivas. In: BALDI, César Augusto (org.). Direitos humanos na sociedade cosmopolita. Rio de Janeiro: Renovar, 2004.

REIS, Rossana Rocha. $\mathrm{O}$ direito à terra como um direito humano: a luta pela reforma agrária e o movimento de direitos humanos no Brasil. Lua Nova: Revista de Cultura e Política, São Paulo, n. 86, p. 89-112, 2012. Disponível em: http://www.scielo.br/scielo.php?script=sci arttext\&pid=S0102-64452012000200004. Acesso em: 10 abr. 2018.

RUBIO, David Sanches. Pluralismo jurídico e emancipação social. In: Wolkmer, Antônio Carlos; NETO, Francisco Q. Veras; LIXA, Ivone M. (orgs). Pluralismo Jurídico: os novos caminhos da contemporâneidade. São Paulo: Saraiva: 2013. p. 51-66.

SAUER, Sérgio. Demanda mundial por terras: "land grabbing" ou oportunidade de negócios no Brasil? In: Revista de Estudos e Pesquisas sobre as Américas, Brasília, v. 4, n. 1, p. 72-88, jan./jun. 2010.

SENGHOR, Léopold Sédar. Colonialismo e neocolonialismo. Lisboa: Heraclio Fournier, 1979.

SOUZA, Murilo. Debatedores divergem sobre projeto que regula compra de terras por estrangeiros. Câmara dos Deputados. Brasília, 14 jul. 2016. Disponível em: http://www2. camara.leg.br/camaranoticias/noticias/AGROPECUARIA/512537-DEBATEDORESDIVERGEM-SOBRE-PROJETO-QUE-REGULA-COMPRA-DE-TERRAS-PORESTRANGEIROS.html. Acesso em: 17 maio 2018.

VELASCO, Juan David. Negociando la tierra: empresas extranjeras, minería a gran escala y derechos humanos en Colombia. In: Estudio Sociojuridico, Bogotá, v.16, n. 1, p. 289-314, jan./ jun. 2014. Disponível em: https://revistas.urosario.edu.co/index.php/sociojuridicos/article/view/ esj16.1.2014.07/2383. Acesso em: 21 abr 2018.

VELOSO, Haroldo. A venda de terras: relatório da comissão parlamentar de inquérito. CNDDA: Rio de Janeiro, 1968.

WOLKMER, Antônio Carlos. Introdução ao pensamento jurídico crítico. São Paulo: Saraiva, 2015.

WOLKMER, Antônio Carlos. Pluralismo jurídico: fundamentos de uma nova cultura no Direito. São Paulo: Alfa-ômega, 1994.

WOLKMER, Antônio Carlos. Pluralismo Jurídico: nuevo marco emancipatório em América Latina. In: VILLEGAS, Maurício García; RODRIGUES, César (orgs). Derecho y sociedad 
em América Latina: um debate sobre los studios jurídicos críticos. Bogotá: ILSA/Universidad Nacional Colombia, 2003.

WOLKMER, Antônio Carlos. Pluralismo Jurídico: um espaço de resistência na construção dos direitos humanos. In: ; VERAS NETO, Francisco Q.; LIXA, Ivone M. (orgs). Pluralismo jurídico: os novos caminhos da contemporâneidade. São Paulo: Saraiva: 2013, p. 37-50.

WOLKMER, Antônio Carlos; LIPPSTEIN, Daniela. Por uma educação latino-americana em direitos humanos: pensamento jurídico crítico contra hegemônico. Revista Direitos e Garantias Fundamentais. Vitória, v. 18, n. 1, p. 283-301, jan./abr. 2017.

ZAIA, Cristiano. Casa Civil quer venda de terra a estrangeiro sem limite de área. Valor Econômico. Rio de Janeiro, 6. abr. 2017. Agronegócio. Disponível em: http://www.valor.com.br/ agro/4928916/casa-civil-quer-venda-de-terra-estrangeiro-sem-limite-de-area. Acesso em: 07 abr. 2018 .

Como citar: RICHTER, Daniela; BRUNET, Karina Schuch; PAUL, Odone Frederico. O land grabbing e a estrangeirização das propriedades brasileiras e a luta contra as novas formas de colonialismo. Revista do Direito Público, Londrina, v. 16, n. 3, p. 144-167, dez. 2021. DOI: 10.5433/24157-108104-1.2021v16n3p.144. ISSN: 1980-511X

Recebido em: 28/01/2020

Aprovado em: 17/05/2020 